\title{
SUSTENTABILIDADE E ESPIRITUALIDADE: EXPERIÊNCIAS DE EDUCAÇÃO AMBIENTAL NA EDUCAÇÃO BÁSICA ${ }^{1}$
}

\section{SUSTAINABILITY AND SPRIRITUALITY: ENVIRONMENTAL EDUCATION EXPERIENCES IN BASIC EDUCATION}

Idulce Ahlert*

Alvori Ahlert**

Resumo:

O presente estudo teve como objetivo pesquisar e descrever um projeto interdisciplinar desenvolvido por uma escola confessional/comunitária no Oeste do Estado do Paraná. A metodologia conjuga a revisão bibliográfica com o nível de pesquisa descritiva para compreender as características das atividades realizadas em Ensino Religioso e Educação Ambiental para a sustentabilidade. Fundamentado na revisão bibliográfica sobre o Ensino Religioso e sobre a sustentabilidade e sua importância no processo educativo, a análise evidencia a articulação entre os vários campos de saberes do currículo escolar proporcionados pelo projeto "Sítio Bier". O desenvolvimento do projeto oportuniza aos alunos a interação e o conhecimento prático sobre a produção orgânica de alimentos de origem animal e vegetal e sobre a importância da reciclagem, do cuidado com os ecossistemas, da capacidade e importância da agricultura orgânica e do desenvolvimento sustentável. Conclui-se que o Ensino Religioso desenvolvido no Colégio Evangélico Martin Luther se constitui como parte importante para a vida dos alunos através de sua articulação com a Educação Ambiental. A abordagem religiosa e os conhecimentos científicos interdisciplinares possibilitam questionamentos mais profundos para todas as disciplinas curriculares e possibilita o aprendizado de conteúdos curriculares de forma lúdica e com uma espiritualidade que desenvolvem o amor e o cuidado com o meio ambiente.

Palavras-chave: Sustentabilidade; Espiritualidade; Educação Ambiental; Ensino Religioso.

\section{Abstract:}

This study aimed to research and describe an interdisciplinary project developed by a confessional/community school in the west of Paraná State. The methodology associates the literature review with the level of descriptive research to understand the characteristics of the activities performed in Religious Education and Environmental Education for sustainability. Based on the literature review on religious teaching and sustainability and its importance in the educational process, the analysis highlights the articulation between the various fields of knowledge of the school curriculum provided by the "Sítio Bier" (Bier's Farm) project. The development of the project provides students with interaction and practical knowledge on the organic production of

1 Enviado em: 20.08.2019. Aceito em: 05.03.2020.

* Pós-Graduada em Gestão Escolar. Graduação em Pedagogia. Professora de Ciências e Ensino Religioso no Colégio Evangélico Martin Luther, Marechal Cândido Rondon, Paraná, Brasil. E-mail: idulceahlert@martinluther.com.br

** Pós-Doutorado em Educação. Doutor em Teologia. Mestre em Educação nas Ciências. Graduado em Teologia. Professor Associado da Universidade Estadual do Oeste do Paraná - UNIOESTE. Atua no Programa de Pós-Graduação em Desenvolvimento Rural Sustentável - PPG-DRS. E-mail alvoriahlert@yahoo.com.br

Protestantismo em Revista | São Leopoldo | v. 45, n. 02 | p. 73-89| Jul./dez. 2019

Disponível em: <http://periodicos.est.edu.br/index.php/nepp> 
animal and plant foods and on the importance of recycling, care for ecosystems, the capacity and importance of organic agriculture and sustainable development. It was concluded that the religious teaching developed at the Martin Luther Evangelical College is an important part of the students' life through its articulation with the Environmental Education. The religious approach and interdisciplinary scientific knowledge enable deeper questions for all curricular subjects and enables the learning of curricular content in a playful and spiritual way that develops love and care for the environment.

Keywords: Sustainability; Spirituality; Environmental Education; Religious Education.

\section{Introdução}

O Ensino Religioso vem reconquistando espaço no debate educacional no Brasil. A partir da segunda metade da década de 80 , buscou-se assegurá-lo como um elemento integrante do sistema escolar. Para isso foi necessário superar a visão da presença eclesial na Escola (ensino de doutrinas religiosas), para configurar o Ensino Religioso como uma disciplina centrada na antropologia religiosa.

Da mesma forma, as últimas décadas do século XX trouxeram para a educação a preocupação com a educação ambiental. A crise ambiental afeta as condições de sustentabilidade do planeta e cria a necessidade de novas metodologias de ensino e aprendizagem capazes de orientar o processo de reconstrução do saber mais amplos e holísticos. Sabe-se que boa parcela das agressões ao meio ambiente deriva do desconhecimento. O não conhecimento sobre a realidade ambiental é uma das maiores ameaças à sustentabilidade, o que se denomina hoje como analfabetismo ambiental. Os seres humanos desconhecem as suas interações com a natureza diante da ausência da consciência ecológica.

Neste contexto surgiu a Educação Ambiental (EA), com o propósito de orientar a resolução dos problemas do meio ambiente. E muito cedo descobriu-se que esta tarefa demanda um processo interdisciplinar. Um processo educativo interdisciplinar e orientado para a resolução dos problemas vem se tornando uma característica da EA. Esta não deve ser compreendida como uma nova disciplina. Sua perspectiva é a contribuição no conjunto das diversas disciplinas e experiências educativas no estudo sobre o meio ambiente.

Neste sentido, o presente estudo tem como objetivo pesquisar e descrever um projeto interdisciplinar desenvolvido por uma escola comunitária no Oeste do Estado do Paraná. Trata-se de um projeto construído a partir do Ensino Religioso e das Ciências da Natureza e que se tornou um projeto interdisciplinar.

Assim, o presente texto se estrutura a partir de uma revisão bibliográfica sobre o Ensino Religioso e sobre a sustentabilidade e sua importância no processo educativo. E, com base nessas discussões, apresentaremos o Projeto "Sítio Bier" desenvolvido pela referida escola comunitária. A descrição do projeto vem acompanhada da compreensão sobre a execução do mesmo mediante resultados de suas vivências e experiências.

Protestantismo em Revista | São Leopoldo | v. 45, n. 02 | p. 73-89| Jul./dez. 2019

Disponível em: <http://periodicos.est.edu.br/index.php/nepp> 


\section{Materiais e método}

Enquanto pesquisa social que busca conhecimentos atualizados sobre uma determinada atividade de uma instituição educacional, para compreender como esta articula seu Ensino Religioso com a Educação Ambiental, nossa pesquisa se constitui como uma revisão bibliográfica "desenvolvida a partir de material já elaborado, constituído principalmente de livros e artigos científicos"2.

Com base nos referenciais sobre o Ensino Religioso e suas inter-relações com a educação para a sustentabilidade, o nível de pesquisa é descritivo, ou seja, conforme Gil, "têm como objetivo primordial a descrição das características de determinada população ou fenômeno" ${ }^{3}$, para, através do projeto "Sítio Bier" e meios fotográficos, descrever as atividades realizadas em Educação Ambiental para a sustentabilidade.

\section{Revisão de literatura}

\section{O Ensino Religioso como componente curricular no Colégio Evangélico Martin Luther}

As primeiras escolas na maioria dos países da América Latina foram construídas pelas igrejas, denominadas hoje como escolas confessionais ou comunitárias. No catolicismo destacaramse as escolas ligadas a ordens religiosas, como os jesuítas, os maristas, os camilianos, os salesianos etc. Também as igrejas protestantes trouxeram a educação como um dos pilares fundamentais de sua missão.

Como igreja de imigração, a Igreja Evangélica de Confissão Luterana no Brasil - IECLB formou comunidades religiosas e sociológicas sustentadas na fé luterana e na educação comunitária. Na primeira década do século XX, a rede de escolas evangélico-luteranas tinha como objetivo desenvolver uma identidade com a função de preparar as lideranças comunitárias. Inicialmente visavam formar pastores e professores dentre pessoas ligadas ao grupo étnico teutobrasileiro que, a partir dessa formação, deveriam construir comunidades confessionais luteranas de bases populares e independentes em solo brasileiro.

Muitas comunidades evangélicas no sul do Brasil desenvolveram suas atividades conjugando, no mesmo ambiente, as atividades escolares e suas celebrações e demais ofícios religiosos. As escolas confessionais, denominadas de comunitárias, exerceram e exercem até hoje um papel importante na tarefa educativa dos cidadãos brasileiros. ${ }^{4}$

No início da década de 70, a IECLB mantinha cerca de 100 escolas de ensino primário ou fundamental e 30 escolas de ensino médio. Entre elas existiam algumas escolas com cursos técnicos. Nesse período, a rede de escolas da IECLB contava com cerca de 20.000 alunos matriculados. Conforme Danilo R. Streck, "Para suprir a lacuna da falta de escolas públicas chegou a haver, nos sínodos, mais de 400 escolas confessionais luteranas, contra as pouco mais de 100 que existem (ou resistem) atualmente". ${ }^{5}$

2 GIL, Antonio Carlos. Métodos e técnicas de pesquisa social. 6. ed. São Paulo: Atlas, 2008. p. 50

GIL, 2008, p. 28

4 STRECK, Danilo R. \& WACHS, Manfredo C. Educação cristã. In: SCHNEIDER-HARPRECHT, Cristoph (Org.). Teologia Prática no contexto da América Latina. São Leopoldo: Sinodal: ASTE, 1998. p. 255

5 STRECK, Danilo Romeu. Perspectiva luterana da educação (IECLB). In: STRECK, Danilo Romeu (Org.). Educação e Igrejas no Brasil: um ensaio ecumênico. São Leopoldo: Ciências da Religião/CELADEC/IEPG, 1995. p. 31

Protestantismo em Revista | São Leopoldo | v. 45, n. 02 | p. 73-89| Jul./dez. 2019

Disponível em: <http://periodicos.est.edu.br/index.php/nepp> 
Já nos primórdios da década de 80, a IECLB criou o Conselho de Educação da IECLB e a Associação Evangélica de Educação, ambos ligados ao Departamento de Educação da igreja. Conforme seus regimentos, o Departamento de Educação tem o objetivo de coordenar as ações da IECLB no campo da educação formal, portanto, gerir sua política educacional, enquanto a Associação Evangélica de Educação e o Conselho de Educação têm como tarefa analisar a realidade escolar e prestar apoio à rede de escolas em suas posições e inserções na realidade educacional brasileira.

Porém, as transformações ocorridas dentro da IECLB e no contexto sócio-político no qual está inserida provocaram, na década de 1990, a reestruturação e adequação nas escolas evangélicas, originando a Rede Sinodal de Educação.

A Rede Sinodal de Educação, constituída pelas escolas filiadas, busca hoje uma expansão em duas frentes. Num crescimento horizontal, quer alcançar as áreas de colonização mais recentes, como, por exemplo, o Instituto Luterano de Educação de Parecis, Campo Novo do Parecis/MT, fundado em 1996. Numa tentativa de verticalização, foram criados cursos de nível superior e de pós-graduação lato sensu, em Curitiba/PR, Joinville/SC, Ivoti/RS, Três de Maio/RS, Horizontina/RS, além da Escola Superior de Teologia que já possuía curso de pósgraduação stricto sensu (mestrado e doutorado) com nível de excelência segundo a avaliação do MEC. ${ }^{6}$

Atualmente a Rede está constituída de 51 escolas, com cerca de 30.000 matrículas na Educação Básica e Ensino Superior, dentre as quais está o Colégio Evangélico Martin Luther, uma escola com Educação Infantil, Ensino Fundamental e Médio, situado no município de Marechal Cândido Rondon, Oeste do Paraná, é uma das escolas filiadas à Rede Sinodal de Educação. Suas atividades tiveram início em 1954, com a vinda dos migrantes luteranos dos estados de Santa Catarina e Rio Grande do Sul. E, como escola confessional, ela mantém desde sua formação o compromisso de ofertar o Ensino Religioso em seu currículo.

Nesta escola, o Ensino Religioso constitui parte importante da vida. Por isso, o mundo que envolve o aluno, a própria natureza do Ensino Religioso exige que se retomem, na aula, conteúdos que estão sendo tratados em outras áreas ou disciplinas. Isto não implica posições rivais. Também não significa uma mera complementação. Seu enfoque é diferente, pois a abordagem religiosa se constitui em horizontes mais vastos e questionamentos mais profundos. Sua tarefa é construir a crítica aos falsos valores que a sociedade vem desenvolvendo diariamente e que afetam a vida humana e seu entorno ambiental. Junqueira, baseado em Goldmann, acredita que,

[...] embora haja fatores não cognitivos que determinam a opção de fé, o pensamento religioso não difere quanto ao modo e à forma do pensamento não religioso [...]. Além disto, deve-se considerar o risco de uma educação que coloca como centro o conteúdo ao invés da criança, enquanto um ser em crescimento podendo promover um retardamento quanto ao desenvolvimento do pensamento religioso ou mesmo um desligar-se de tais questões, ao menos no nível cognitivo. Com isso, a pessoa estaria abdicando de um dos elementos que perfazem a integridade humana, ou seja, a razão. ${ }^{7}$

Por isso a escola confessional não pode determinar e impor uma educação confessional. Entretanto, o autor se fundamenta em Batista e Pohier para justificar a importância da

6 AHLERT, Alvori. Educação, ética e cidadania: referenciais para as escolas da Rede Sinodal de Educação. Beau Bassin, Mauritius: Novas Edições Acadêmicas, 2018. p. 209

7 JUNQUEIRA, Sérgio. O processo de escolarização do Ensino Religioso no Brasil. Petrópolis, RJ: Vozes, 2002 , p. 98.

Protestantismo em Revista | São Leopoldo | v. 45, n. 02 | p. 73-89| Jul./dez. 2019

Disponível em: <http://periodicos.est.edu.br/index.php/nepp> 
aprendizagem da fé no contexto do ensino e da aprendizagem escolar como um importante valor na formação integral dos educandos. Neste sentido, cita dois importantes estudos sobre a questão:

Outro estudo neste sentido foi realizado no Brasil pela Ir. Terezinha Batista, em seu livro Evolução da fé na criança, em que se constata como é importante a ação e a imitação nos primeiros anos de vida, verificando que o papel do ambiente é componente acelerador para o desenvolvimento da fé. Se pretendemos um caminhar tranquilo para a criança neste processo, o melhor recurso é o diálogo que faça crescer na confiança em Deus e nos irmãos. Um terceiro estudo encontramos em Psicologia da inteligência e psicologia da fé, de J. M. Pohier, que faz uma releitura de Piaget do ponto de vista da teologia. O autor propõe que, ao atuarmos no campo do religioso contribuiremos para a maturidade da fé, na medida em que provoquemos a possibilidade de dar a Deus o lugar de Deus, através de um processo de construção e da diferenciação entre o eu o outro, o eu e o mundo, e o eu a Deus (que para Pohier se encontra em Cristo), pois a fé madura é uma fé aberta ao mundo, que não teme sucumbir diante de outras ideias e crenças, resultando em um equilíbrio entre o cognitivo. $^{8}$

Diante disso, e orientado por estas perspectivas, podemos afirmar que a proposta de trabalho do Ensino Religioso no Colégio Evangélico Martin Luther está baseada no respeito à diferença. Respeitar o outro como um ser diferente, pois ele tem uma história diferente. Constituiuse por meio de manifestações culturais diferentes, que não são mais ou menos importantes do que qualquer outra, e por isso manifesta de forma diferente a sua religiosidade. No entanto, numa perspectiva do Ensino Religioso confessional, tal constatação criava diferenças. Por isso se justifica um Ensino Religioso como componente curricular que paute seu trabalho em uma nova visão, ou seja, na perspectiva de ciência da religião.

A nova visão exige um tratamento didático proposto que é o de caracterizar o aluno, com a coerência do objetivo da série, realizar encaminhamento para avaliação da aprendizagem, realizada por blocos de conhecimentos. Portanto, observação - reflexão - informação são os percursos metodológicos selecionados que, como estratégia, propõe o convívio social, assim como as relações com as culturas e tradições religiosas. ${ }^{9}$

Este perfil do Ensino Religioso torna-se um espaço escolar que precisa levar em conta toda a dinamicidade e os fatos que constituem as sociedades complexas de nossos dias. $E$ isto lhe abre possibilidade de um salto de qualidade muito importante apresentado a seguir:

O Ensino Religioso é parte integrante da formação básica do cidadão (Res. CEB 02/98 da Câmara de Educação Básica); no Ensino Religioso, tal como definido na Lei, é assegurado o respeito à diversidade cultural religiosa do Brasil, sendo-lhe impedidas todas as formas de proselitismo; a resolução CEB N 02/98 reconhece o Ensino Religioso como área de conhecimento ao lado de todas as outras construtivas do currículo escolar; a mesma Resolução inclui o Ensino Religioso, porque entendido como área de conhecimento, como integrante da Base Comum Nacional da educação brasileira; à escola compete garantir o acesso dos discentes ao conhecimento religioso, em seus múltiplos aspectos, pois o que se quer é um Ensino Religioso agregador, de tal forma que católicos, evangélicos, budistas, membros de ritos afro-brasileiros e outros, e sentem lado a lado e se sintam aceitos pelos colegas, sem se sentirem inferiorizados; assumir esta posição significa lidar com o

8 JUNQUEIRA, 2002, p. 98.

9 JUNQUEIRA, 2002, p. 99.

Protestantismo em Revista | São Leopoldo | v. 45, n. 02 | p. 73-89| Jul./dez. 2019

Disponível em: <http://periodicos.est.edu.br/index.php/nepp> 
conhecimento sobre o Ensino Religioso e não com a fé, papel este reservado às diversas tradições religiosas nos seus locais específicos de exercício religioso [...]. ${ }^{10}$

Assim, o Ensino Religioso, como parte integrante do currículo para a Educação Básica, é concebido como não proselitista, respeitando as diferenças e alinhando-se no conjunto de saberes capazes de proporcionar uma vivência da cidadania, tanto para os alunos e alunas quanto para o universo escolar enquanto estrutura institucional.

\section{O Ensino Religioso como construção de valores transcendentes}

O Ensino Religioso, que visa a uma educação plena do aluno, a formação de valores fundamentais através da busca do transcendente e da descoberta do sentido mais profundo da existência humana, oportuniza esta busca na construção de valores transcendentes. Portanto, no Colégio Evangélico Martin Luther não se ignora o Ensino Religioso no processo da educação, não se despreza a pessoa humana, nem se violenta ela naquilo que tem de mais íntimo, sua religiosidade, bem como não se viola seu direito a uma educação completa, desrespeitando sua liberdade de cidadão, que inclui o direito de pensar e expressar livremente suas ideias e religião.

E é neste sentido que o Ensino Religioso nesta escola é uma disciplina que adota uma metodologia que proporciona ao aluno o desenvolvimento de sua capacidade de reflexão, firmado nos valores relacionados à vida, à ética, ecologia, paz, solidariedade, justiça, fraternidade e cultura, o que é comum a todas as religiões. Lembramos aqui a fala de Catão, sobre o tema ética e religião, trazendo os valores do transcendente: "Buscando a verdade, o amor e a justiça, o bem, enfim, na multiplicidade indefinida dos outros que se vai encontrando na caminhada dessa vida, é sempre o Outro que o ser humano está buscando". ${ }^{11}$

Quando falamos dos fundamentos epistemológicos do Ensino Religioso, este deve cultivar esperança naquilo que a escola precisa desenvolver, isto é, a capacidade de observação, de reflexão, de criação, de discernimento, julgamento, comunicação, convívio, cooperação, ética do cuidado com o meio ambiente, decisão e ação frente à realidade da vida.

\section{A educação para a sustentabilidade na educação básica}

A educação para a sustentabilidade é um dos conteúdos da Educação Ambiental. "Hoje, o discurso da Educação Ambiental está voltado para o desenvolvimento sustentável, buscando uma qualidade de vida para todos os seres vivos e para as gerações futuras". ${ }^{12}$ Entretanto, sabe-se que, "[...] a educação ambiental ainda não perpassa suficientemente os espaços escolares quando não é articulada aos ambientes biossociais que compreendem a unidade de conservação e todos os aspectos coadjuvantes para o enriquecimento de conteúdos e propostas escolares". ${ }^{13}$ Por isso, a

10 JUNQUEIRA, Sérgio Rogério Azevedo, MENEGHETTI, Rosa Gitana Krob, WASCHOWICZ, Lilian Anna. Ensino Religioso e sua relação pedagógica. Petrópolis: Vozes, 2002. p. 54-55.

11 CATÃo, Francisco. Diálogo - Revista da Religião. N. 11, São Paulo: Paulinas, Agosto, 1998. p. 180.

12 PREDIGER, Caroline Luzia; AHLERT, Alvori. Ética e Educação Ambiental: Lugares Privilegiados na Apicultura. Ensaios e Cienc., v. 22, n. 2, 2018. Disponível em: https://revista.pgsskroton.com.br/index.php/ensaioeciencia/article/view/5550/4589. Acesso em: 16 ago. 2019 , p. 73.

13 ROCHA, Keili., AHLERT, Alvori., \& CARNIATTO, Irene. Área de Relevante Interesse Ecológico (ARIE) como espaço privilegiado para a Educação Ambiental. Revista Brasileira De Educação Ambiental (RevBEA), 12(4), 2017. Disponível em: http://revbea.emnuvens.com.br/revbea/article/view/4964. Acesso em: 05 ago. 2019, p. 23.

Protestantismo em Revista | São Leopoldo | v. 45, n. 02 | p. 73-89| Jul./dez. 2019

Disponível em: <http://periodicos.est.edu.br/index.php/nepp> 
importância de a educação para a sustentabilidade articular-se com o aprendizado da produção orgânica de alimentos de origem animal e vegetal enquanto atividade componente e indispensável aos processos educativos da educação básica.

Um ensino religioso que motiva para o cuidado com a vida e o bem estar da criação de Deus contribui para uma educação para a sustentabilidade quando se articula interdisciplinarmente aos sistemas orgânicos de produção, que normalmente incluem grãos, frutas e hortaliças, pois integra o solo, as plantas e os animais de forma sustentável sem deixar de lado a harmonia com o ambiente, a produtividade e a rentabilidade para o produtor. Os animas para a produção de leite, carnes, ovos e derivados configuram um ciclo através do qual os dejetos por eles produzidos, incorporados a outros resíduos vegetais, dão origem a compostos orgânicos que, por sua vez, se transformam em fertilizantes para a produção de alimentos.

Dessa forma as escolas podem construir projetos pedagógicos que integram a Educação Ambiental em seus currículos, para que desenvolvam dinâmicas de interação entre a escola e a natureza.

Cabe aos processos de Educação Ambiental, inseridos no currículo, refletir sobre a dinâmica da relação sociedade-natureza, nos quais, sem esta dimensão, tornam o debate ambiental simplificado, enquanto o ensino for fragmentado e despolitizado pela negação da materialidade e das contradições contidas nas relações sociais. ${ }^{14}$

No caso do ensino e da aprendizagem de Ciências no Ensino Fundamental, Marilei Aparecida Gionedis Wilsek e João Angelo Pucci Tosin, defendem que a dinâmica da disciplina pode e deve ser enriquecida através de atividades de pesquisa e resolução de problemas constituindo o estudante como sujeito de aprendizagens mediante a interação como os professores, colegas e com o meio. Os referidos autores se fundamentam na teoria de Vygotsky ao afirmarem:

Valorizar o que o estudante já sabe (conhecimento cotidiano) e consegue efetivamente fazer ou resolver por ele mesmo (nível de desenvolvimento real) e o que o estudante ainda não sabe, mas pode vir, a saber, com a mediação do professor (nível de desenvolvimento pessoal), de acordo com o conceito ZDP (Zona de Desenvolvimento Proximal) de Vygotsky. São considerados três aspectos essenciais para o Ensino de Ciências, tanto para a formação do professor quanto para a atividade pedagógica. ${ }^{15}$

A reflexão sobre as práticas sociais, religiosas e ambientais em um contexto marcado pela degradação permanente do meio ambiente e do seu ecossistema, envolve estratégias de produção de sentidos para a educação ambiental. Dentre muitas possibilidades, trabalhar de forma interdisciplinar com o Ensino Religioso, possibilita refletir e trabalhar conteúdos como a vida e o ambiente, a preservação e a decomposição dos solos (permeabilização, fertilidade, erosão), da água, do ar e a interação do ambiente com os seres vivos, a constituição e nutrientes do solo, as espécies vegetais e o desenvolvimento das plantas, a luminosidade, a temperatura e a fotossíntese, a importância dos insetos, o ser humano e a saúde, as doenças transmitidas pela água, pelo solo e pelo ar, a nutrição e a alimentação, a preservação do meio ambiente e da saúde, a gestão de

14 KOPPE; AHLERT; CARNIATTO, 2018, p. 256.

15 WILSEK, Marilei Aparecida Gionedis, TOSIN, João Angelo Pucci. Ensinar e aprender Ciências no Ensino Fundamental com atividades investigativas através da resolução de problemas. Programa de Desenvolvimento da Educação, PDE, SEED-PR, 2008. Disponível em: www.diaadiaeducacao.pr.gov.br/portals/pde/arquivos/1686-8.pdf. Acesso em 25 Mai. 2019, p. 8.

Protestantismo em Revista | São Leopoldo | v. 45, n. 02 | p. 73-89| Jul./dez. 2019

Disponível em: <http://periodicos.est.edu.br/index.php/nepp> 
resíduos e a compostagem como um complexo processo dinâmico e permanente da boa e bela criação de Deus.

Do ponto de vista da Educação Ambiental desde o Ensino Religioso, significa ajudar aos alunos a perceberem as necessárias novas ações e alternativas de um novo desenvolvimento, numa perspectiva que priorize novo perfil de desenvolvimento, com ênfase na sustentabilidade socioambiental. Daí adotarmos aqui o conceito de sustentabilidade encontrado nos escritos do teólogo Leonardo Boff, para quem sustentabilidade

[...] é o conjunto dos processos e ações que se destinam a manter a vitalidade e a integridade da Mãe Terra, a preservação de seus ecossistemas com todos os elementos físicos, químicos e ecológicos que possibilitam a existência e a reprodução da vida, o entendimento das necessidades das presentes e das futuras gerações, e a continuidade, a expansão e a realização das potencialidades da civilização humana em várias expressões. ${ }^{16}$

Se fizermos um pacto na centralidade do cuidado com a natureza, poderemos construir estratégias ecologicamente sustentáveis, alinhando as práticas humanas com ações voltadas para a visão de sustentabilidade, e também garantir de forma saudável os recursos da natureza para as necessidades das presentes e futuras gerações.

\section{Discussão e resultados - descrição do "Projeto Sítio Bier"}

\section{Educação, sustentabilidade e espiritualidade no "Projeto Sítio Bier"}

O projeto, desenvolvido pelo Colégio Evangélico Martin Luther, uma escola confessional/comunitária situada na cidade de Marechal Cândido Rondon, Oeste do Estado do Paraná, e vinculada à Rede Sinodal de Educação, tem como princípio contribuir para que os alunos desenvolvam uma formação integral, com base em princípios luteranos, baseada em atitudes de cidadãos críticos e com autonomia, para compreensão da realidade e o entendimento de processos sociais, científicos, culturais e ambientais.

[...] o trabalho da educação científica é conseguir que os alunos construam, na sala de aula, atitudes, procedimentos e conceitos que não conseguiriam elaborar sozinhos em contextos cotidianos e que, sempre que esses conhecimentos sejam funcionais, saibam transferi-los para novos contextos e situações. ${ }^{17}$

Neste sentido, o "Projeto Sítio Bier" visa estimular a curiosidade através do diálogo e promover pesquisas para a aplicação de conceitos nas situações que irão encontrar no seu dia a dia. O foco do projeto está em estabelecer relações entre o conhecimento, o ser humano, as plantas, animais e o meio físico e social. Quando a ecologia chega na escola de forma interdisciplinar, acontece o debate entre alunos, pais, professores sobre a necessidade de se conhecer a dinâmica do meio ambiente e os limites da ação do ser humano para uma boa convivência e para sua própria preservação. No caso do ensino de Ciências da Natureza, "[...] consegue fazer com que os alunos e

16 BOFF, Leonardo. Sustentabilidade: o que é: o que não é. 5. ed. Revista e ampliada. Petrópolis, RJ: Vozes, 2016, p. 14.

17 PAZZO, Juan Ignácio; CRESPO, Miguel Angel G. A aprendizagem e o ensino de ciências: do conhecimento cotidiano ao conhecimento científico. Tradução de Naila Freitas. 5. ed. Porto Alegre: Artmed, 2009, p. 245.

Protestantismo em Revista | São Leopoldo | v. 45, n. 02 | p. 73-89| Jul./dez. 2019

Disponível em: <http://periodicos.est.edu.br/index.php/nepp> 
futuros cidadãos sejam capazes de enfrentar situações cotidianas, analisando-as e interpretando-as através dados modelos conceituais e também dos procedimentos próprios da Ciência". ${ }^{18}$

O "Projeto Sítio Bier" é desenvolvido pelo Colégio Evangélico Martin Luther desde 2016. Para avançar na direção de uma educação para a sustentabilidade, o projeto tem como objetivo principal conhecer e apropriar-se dos conhecimentos sobre sustentabilidade, a fim de incorporar temas relevantes de acordo com cada momento da história.

Ao longo de cada ano, o Colégio Evangélico Martin Luther desenvolve o estudo de temas relacionados com o meio ambiente, para que os educandos possam refletir sobre a natureza do conhecimento e do lazer científico e tecnológico. Os conteúdos são desenvolvidos a partir de experimentos e práticas de vivências em um sítio com selo de produtos orgânicos, para que o aluno comece a formular o conhecimento científico mediante a observação, a experimentação e a comparação.

Os alunos fazem visitas de um dia inteiro no Sítio Bier, localizado próximo à cidade de Marechal Cândido Rondon, de forma que tenham contato com métodos sustentáveis, com o intuito de serem estimulados através da horta para a produção de uma alimentação com a utilização de adubos orgânicos e livre de agrotóxicos degradantes do solo e de adubos químicos.

Grupo de alunos e alunas no Sítio Bier com a professora Idulce Ahlert e o casal Herbert e Hildegard Bier

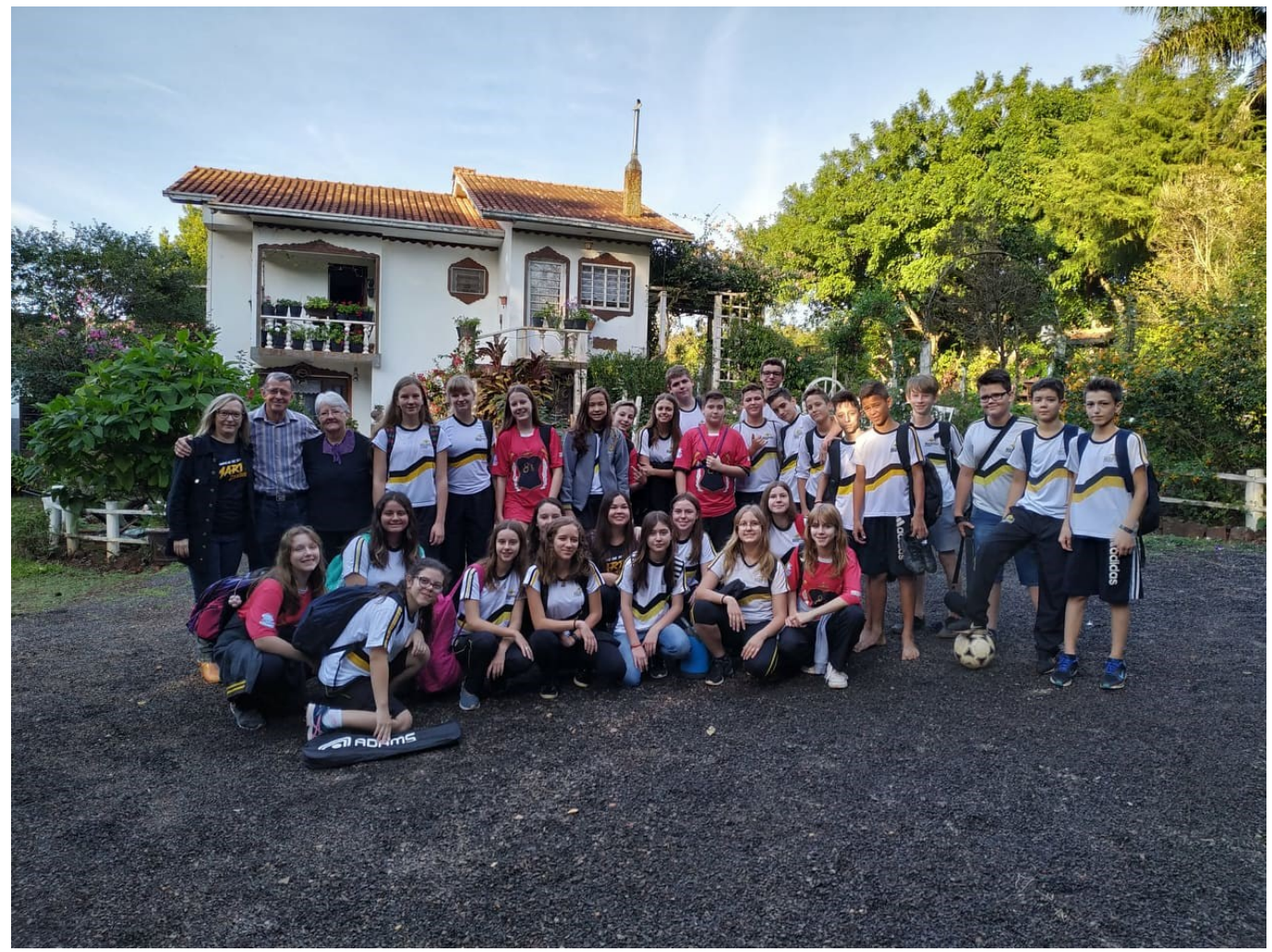

Fonte: Os autores, 2019.

Como objetivo geral, o projeto visa desenvolver nos alunos a capacidade de debater os assuntos concernentes à sustentabilidade ambiental e global com seus colegas e professores, para que ocorra a troca de saberes sobre o tema, a elaboração de hipóteses, experimentações,

18 MALAFAIA, Guilherme; RODRIGUES, Aline S. de L. Uma reflexão sobre o ensino de ciências no nível fundamental da educação. Ciência e Ensino, v. 2, n. 2, 2008, p. 2.

Protestantismo em Revista | São Leopoldo | v. 45, n. 02 | p. 73-89| Jul./dez. 2019

Disponível em: <http://periodicos.est.edu.br/index.php/nepp> 
interpretação de resultados e conclusões. Assim, possibilita-se aos alunos suposições e o desenvolvimento da sensibilidade com relação ao cuidado com a natureza.

Objetivos específicos do projeto são conhecer e debater referenciais bibliográficos e vídeos sobre sustentabilidade, recursos naturais, produção de alimentos convencionais e orgânicos, agricultura sintrópica, 3 Rs (reciclagem, reutilização e redução) da produção de lixo. Também se busca proporcionar uma experiência que ajude a construir a consciência ambiental e o conhecimento da produção orgânica de alimentos, além de promover a integração dos alunos do $6^{\circ}$ ao $9^{\circ}$ ano do Ensino Fundamental II e Ensino Médio.

Ainda dentro de seus objetivos específicos está o desafio de construir atividades de campo na horta escolar, para estimular o religare do ser humano com a natureza, resgatando os costumes de cuidar do ambiente em que se vive, produzindo parte de sua alimentação de forma sustentável, diminuindo o lixo gerado e utilizando de forma sustentável os recursos naturais.

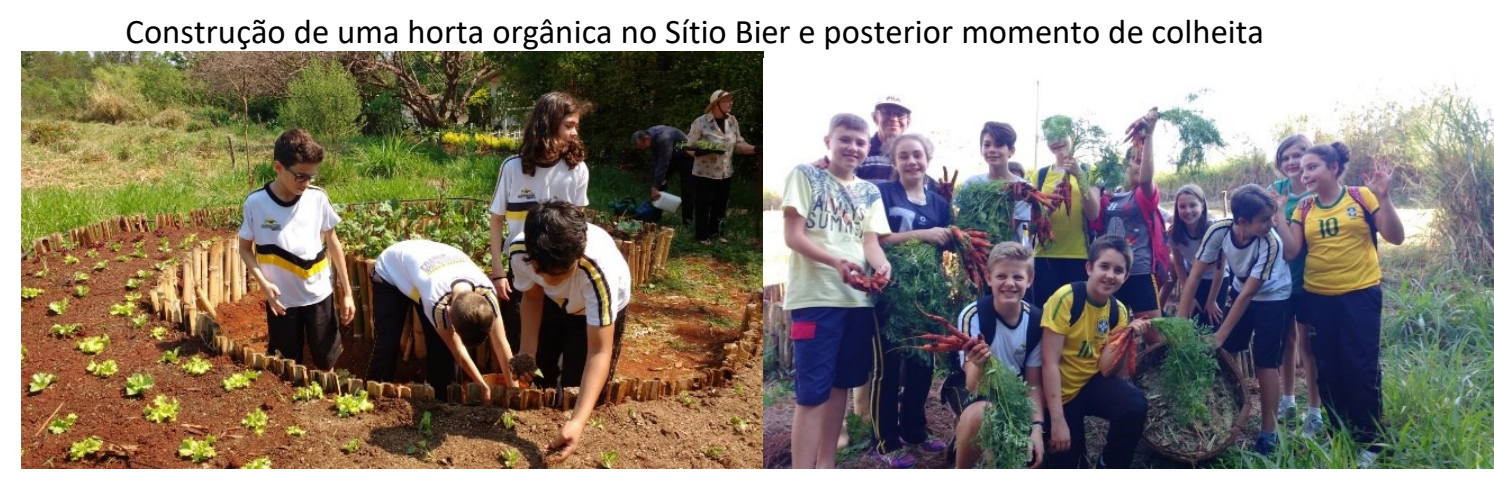

Fonte: Os autores, 2017.

Fonte: Os autores, 2018.

Em resumo, objetiva-se gerar conhecimentos para que os estudantes possam desenvolver o respeito e uma relação de sensibilização com o meio ambiente, entendendo o processo dos sistemas orgânicos de produção animal e vegetal.

Para incorporar temas relevantes de acordo com cada momento da história, a educação precisa estar em constante processo evolutivo. Neste sentido, o caso do ensino de sustentabilidade na escola é um dos temas mais atuais e pertinentes. Além disso, o assunto se coloca como uma urgência imprescindível devido ao contexto das relações entre homem e meio ambiente.

São desenvolvidas atividades cooperativas para um pensar e um fazer interdisciplinar, considerando a diversidade de saberes e o espaço de cada pessoa e de cada grupo. Aqui se evidencia a preocupação de Junqueira quando desafia o Ensino Religioso para uma nova visão didática que seja eficaz para que os alunos vivam a experiência da "observação - reflexão - informação são os percursos metodológicos selecionados que, como estratégia, propõe o convívio social, assim como as relações com as culturas e tradições religiosas." ${ }^{19}$ No caso específico do Projeto, a conexão com a natureza desde um lugar de fé que vincule a espiritualidade com os saberes científicos.

Construção de um tanque para peixes e situação atual

19 JUNQUEIRA, 2002, p. 99.

Protestantismo em Revista | São Leopoldo | v. 45, n. 02 | p. 73-89| Jul./dez. 2019

Disponível em: <http://periodicos.est.edu.br/index.php/nepp> 


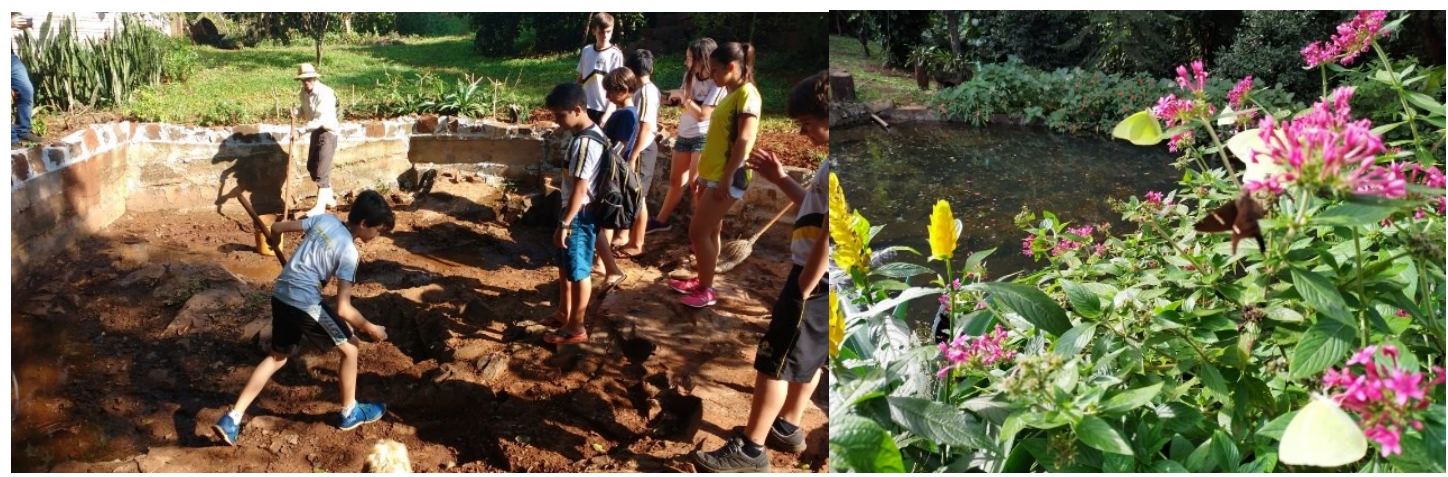

Fonte: Os autores, 2018.

Fonte: Os autores, 2019.

Entendemos que a educação necessita lançar um olhar mais à frente, a fim de organizar e dar sentido à existência do ser humano no planeta através da constituição de uma relação de cuidado com as dimensões de movimento, dinamicidade, sensibilidade, flexibilidade, lúdico, criatividade, processos dialógicos, aprendizagens significativas e avaliação.

Produzir de forma orgânica, natural, alimentos de origem animal e vegetal é uma atividade componente e indispensável para educar as novas gerações num contexto baseado numa espiritualidade que cultiva o Deus da vida como doador e mantenedor dessa vida. Por isso Ele permitiu o desenvolvimento de complexos sistemas orgânicos de produção e auto reprodução. Para a alimentação humana e animal isso inclui a produção saudável de grãos, frutas e hortaliças que integra aos saberes científicos um conhecimento sobre os solos, as plantas e os animais de forma sustentável, sem deixar de lado a harmonia com o ambiente, a produtividade e a rentabilidade para o agricultor que produz os alimentos. Significa possibilitar aos alunos o conhecimento in loco sobre os animais que, além de produzirem leite, carne e ovos, fornecem dejetos que, incorporados a outros resíduos vegetais, dão origem a compostos orgânicos utilizados como fertilizantes naturais dessa complexa criação divina.

Palestra com doutoranda em Desenvolvimento Rural Sustentável, do PPG-DRS, UNIOESTE

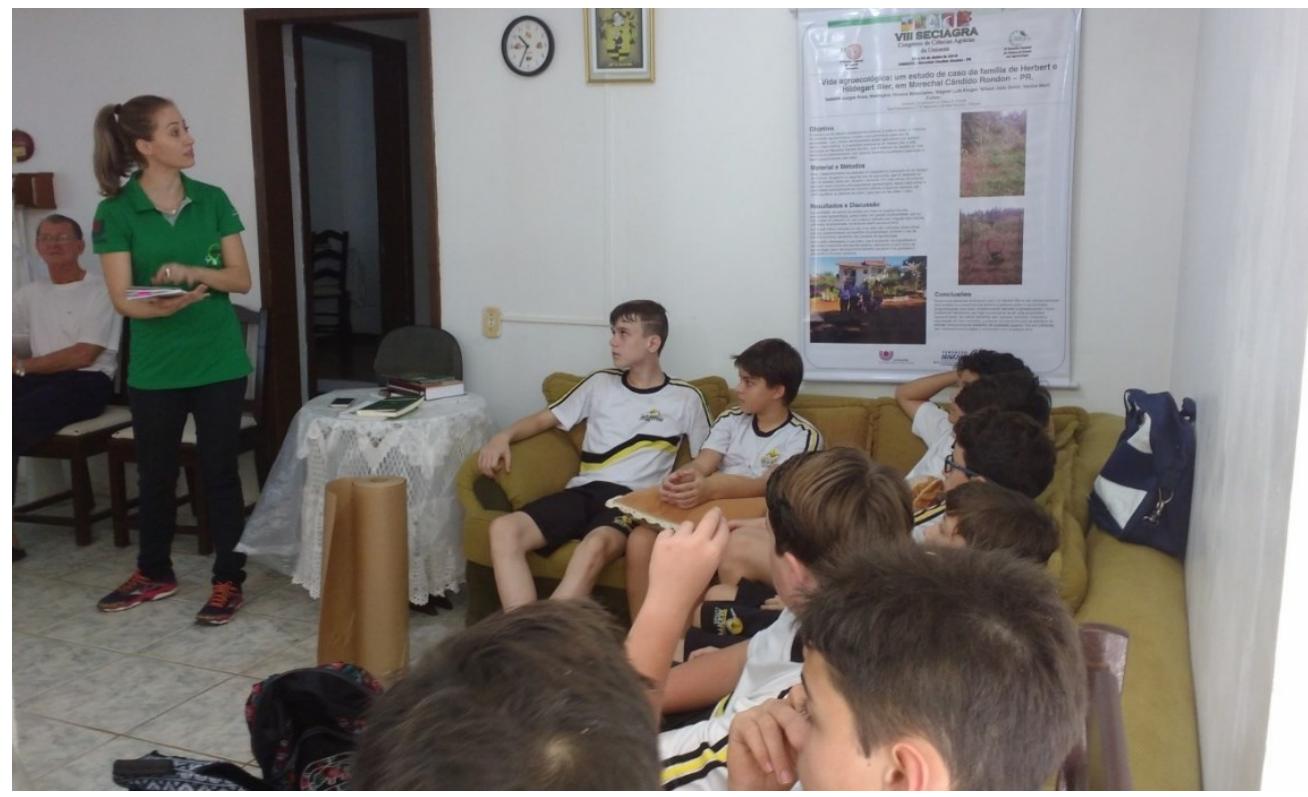

Fonte: Os autores, 2018.

A metodologia do "Projeto Sítio Bier" consiste em trabalhar de forma interdisciplinar. As temáticas são relacionadas com os conteúdos da base curricular de cada disciplina envolvida nas salas de aula. Ocorre toda uma preparação para as visitas técnicas e interativas na propriedade de

Protestantismo em Revista | São Leopoldo | v. 45, n. 02 | p. 73-89| Jul./dez. 2019

Disponível em: <http://periodicos.est.edu.br/index.php/nepp> 
produção orgânica de alimentos. Para trabalhar a sustentabilidade na escola, associada ao Projeto, é importante que exista um envolvimento do aluno, tanto no nível teórico quanto também na prática. Por isso, realizar ações sustentáveis é um bom caminho para engajar os jovens nesta mentalidade mais crítica sobre o uso dos recursos naturais e o relacionamento com o meio ambiente.

Um exemplo dessa prática é a construção de uma composteira. Mediante esta atividade os alunos têm contato direto com uma técnica simples de reutilização de restos de alimentos, o que também contribui para um destino mais adequado do lixo gerado na escola. A composteira produzirá parte do adubo utilizado na horta, fechando um ciclo de resíduos orgânicos.

Construção de uma composteira no Sítio Bier

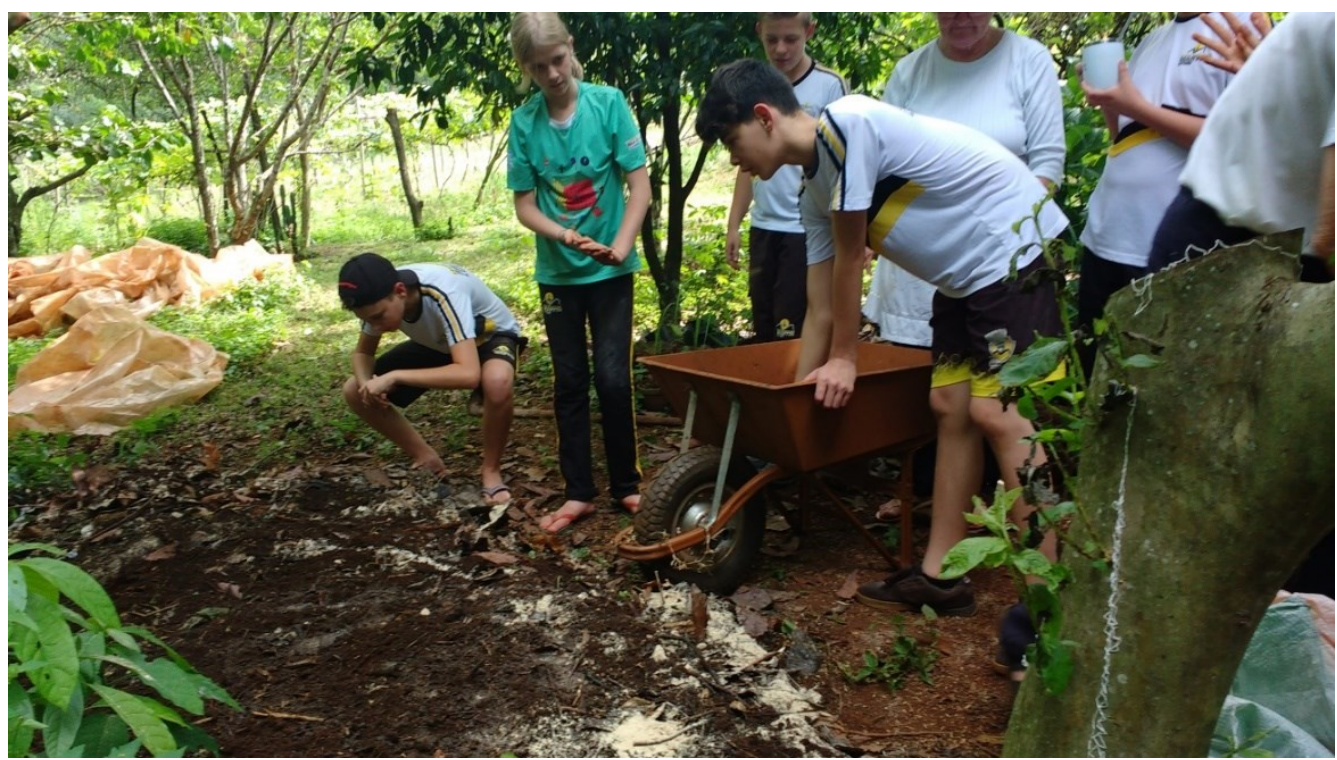

Fonte: Os autores, 2018.

São realizadas atividades uma vez ao ano com cada turma de alunos do $6^{\circ}$ ao $9^{\circ}$ ano do Ensino Fundamental II e do Ensino Médio. Nestes encontros são criados conceitos ambientais em conjunto com os alunos, tais como: reciclagem, ecossistemas, agricultura orgânica, desenvolvimento sustentável, água, ar, problemas ambientais locais etc. Através das atividades práticas, sensibilizações, textos, desenhos, jogos, brincadeiras e filmes motivacionais, facilita-se a compreensão de conteúdos curriculares de forma lúdica e prazerosa.

A espiritualidade desenvolvida nas atividades tem como objetivo trabalhar com os alunos o cuidado com o meio ambiente, compreendido como a boa criação de Deus, e que deve ser como uma resposta ao amor redentor de Deus. Juntamente com ele, todos podemos e devemos ser cuidadores, criadores e mantenedores para proteger o direito e a dignidade da vida das gerações atuais e futuras. Isto significa que tudo o que existe na natureza precisa ser cuidado para que possa continuar a existir.

Aqui o "Projeto Sítio Bier" mostra sua inter-relação com o Ensino Religioso ao desenvolver uma metodologia que leva o aluno ao desenvolvimento de sua capacidade de reflexão, firmado nos valores relacionados à vida, à ética, ecologia, paz, solidariedade, justiça, fraternidade e cultura, o que é comum a todas as religiões, conforme discutimos no referencial teórico acima. São os desafios

Protestantismo em Revista | São Leopoldo | v. 45, n. 02 | p. 73-89| Jul./dez. 2019

Disponível em: <http://periodicos.est.edu.br/index.php/nepp> 
elencados por Catão ${ }^{20}$, isto é, a lembrança de que a metodologia do Ensino Religioso deve se pautar sobre o tema ética e religião, trazendo os valores do transcendente.

Início das atividades com espiritualidade no Sítio Bier

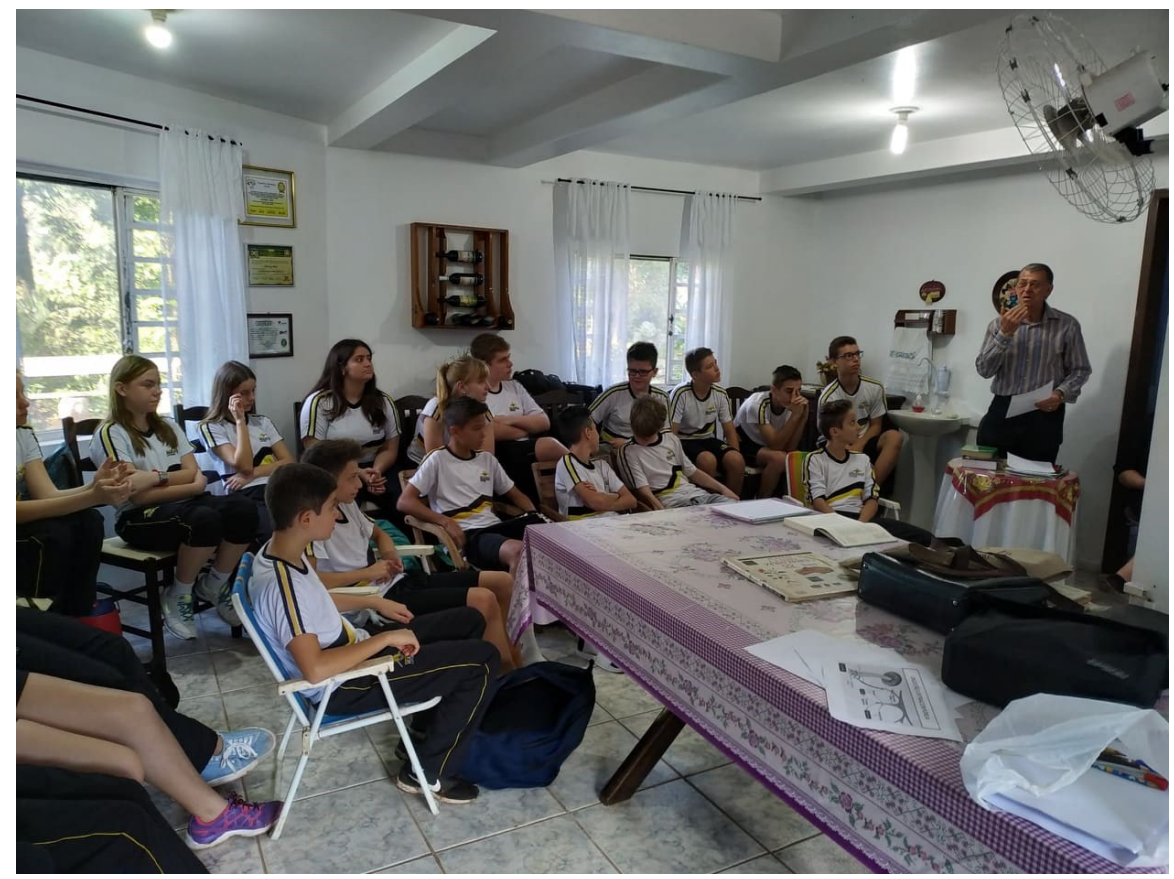

Fonte: Os autores, 2018.

As visitas no Sítio Bier são de um dia inteiro de atividades de integração, reflexão, pesquisas, contatos e convívios com a natureza na perspectiva do aprendizado sobre a importância do desenvolvimento sustentável. Para cada grupo de alunos são elegidos temas diferentes, assessorados por especialistas na área.

Quadro 1 - Programa de atividades no Sítio Bier

\section{PROGRAMA EDUCAÇ̃̃O AMBIENTAL SÍTIO BIER}

A fim de que os educandos possam refletir sobre a natureza do conhecimento a partir do lazer científico e tecnológico, o Colégio Evangélico Martin Luther proporciona atividades diversificadas sobre temas relacionados com o meio ambiente em um sítio no nosso município (próximo ao Clube Roda d'Água). Os conteúdos são desenvolvidos a partir de experimentos e práticas de vivência nesse sítio, que conta inclusive com selo de produção de produtos orgânicos. Lá o aluno começa a formular o conhecimento científico a partir de observações, experimentações e comparações. Após essa experiência, ele terá condições de debater o assunto com colegas e professores, momento em que ocorre a elaboração de hipóteses e suposições, bem como a troca de conhecimento e desenvolvimento de sua sensibilidade em relação ao cuidado com a natureza. Considerando que a Educação Ambiental é um tema interdisciplinar, este processo ocorre em perspectiva de aprofundamento dos conhecimentos. Por isso, as atividades ocorrem em todos os anos do ensino fundamental Il e ensino médio, acompanhando a evolução dos conteúdos relacionados a cada disciplina.

\section{PROGRAMA 2019}

7 h30 - Saída do colégio para o sítio do casal Bier

$8 \mathrm{~h}$ - Chegada: acolhida do sr. Herbert e da sra. Hildegard Bier

"JURAMENTO A FAVOR DA NATUREZA"21.

$8 \mathrm{~h} 30$ - Palestra com sr. Herbert Bier. Tema: Plantas PANCS (Plantas Alimentícias Não Convencionais) $10 \mathrm{~h}$ - Intervalo com lanche

20 CATÃo, Francisco. Diálogo. Revista da Religião. n. 11, São Paulo: Paulinas, Agosto, 1998.

21 "JURAMENTO. Comprometo-me a colaborar em todas as atividades de hoje no Sítio Bier, com a intenção de melhorar as relações humanas e o ambiente. Respeitarei todos os seres vivos (vegetais e animais). Sempre colocarei o lixo nas respectivas lixeiras. Procurarei manter os espaços à minha volta limpos e bem cuidados. Comprometo-me a não usar palavrões e agressões neste lugar de paz e sossego. Assim eu prometo!"

Protestantismo em Revista | São Leopoldo | v. 45, n. 02 | p. 73-89| Jul./dez. 2019 
10h30 - Atividade relacionada com Educação Ambiental. Momento de Espiritualidade sobre "O relógio perdido"22, baseado no Salmo 119.114.

Estudos científicos: Atividades sobre fungos e atividades artísticas

$12 \mathrm{~h}$ - Almoço

$13 \mathrm{~h} 30$ - Atividades de integração

$16 \mathrm{~h}$ - Retorno

Obs.: Levar chinelos, toalha (mais velha) e um copo NÃO descartável. Para lanches: importante levar alimentos considerados saudáveis.

O custo por aluno será de $\mathbf{R} \mathbf{3 0 , 0 0}$ - para despesas de almoço, transporte e taxa de limpeza do local.

Para participar na atividade, solicitamos que a autorização abaixo seja preenchida e entregue na secretaria do Colégio Evangélico Martin Luther, juntamente com o valor acima especificado, até o dia 17/06/2019 (segundafeira).

Data prevista para o programa: 19/06/2019 (Quarta-feira)

Atenciosamente,

Equipe Pedagógica

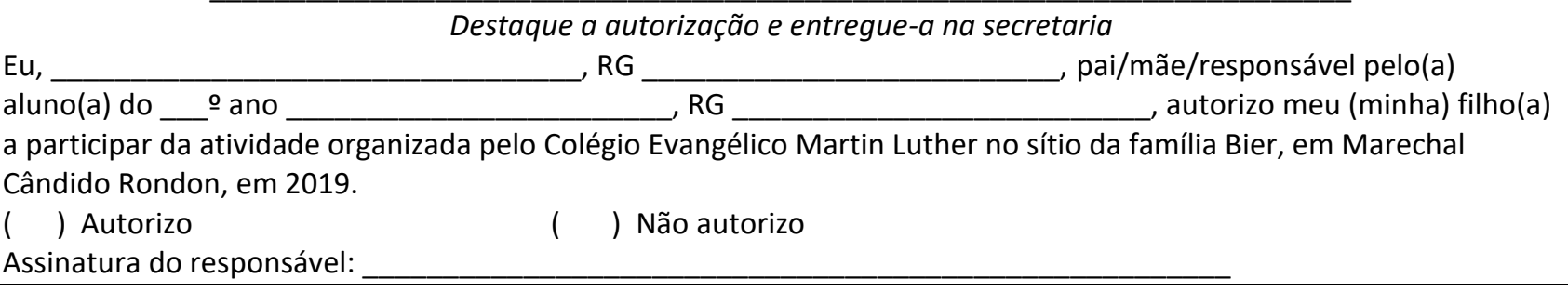

Fonte: Colégio Evangélico Martin Luther, 2019

Na perspectiva da interdisciplinaridade, em uma das visitas de 2019, conforme o Quadro 1 acima, as atividades desenvolvidas oportunizaram a produção de arte com natureza. Na figura abaixo, pode-se observar essa atividade de arte e seus resultados, que depois foram expostos no Colégio Evangélico Martin Luther.

Atividades de arte com natureza
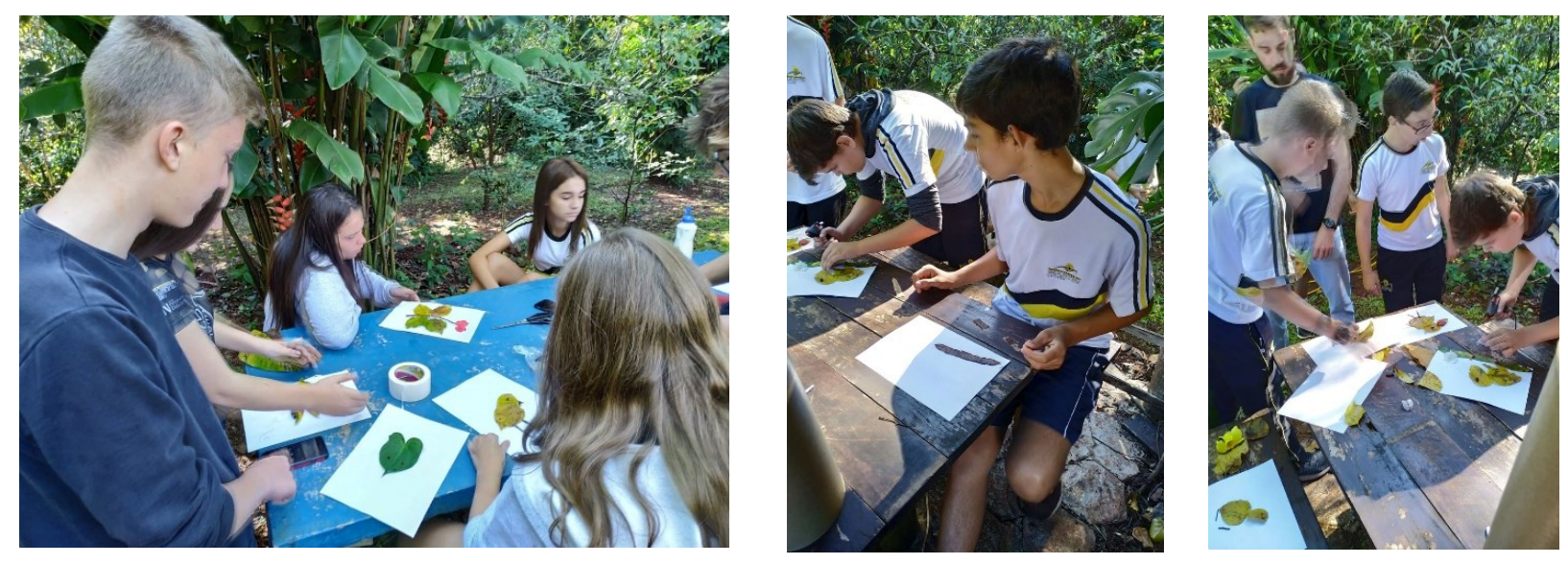

22 WENDLAND, Carlos Ernesto. O relógio perdido. In: NEUHAUS, Elói Bruno (Org.). Semente de esperança. Palmitos: PPL, 2019. p. 12.

Protestantismo em Revista | São Leopoldo | v. 45, n. 02 | p. 73-89| Jul./dez. 2019

Disponível em: <http://periodicos.est.edu.br/index.php/nepp> 

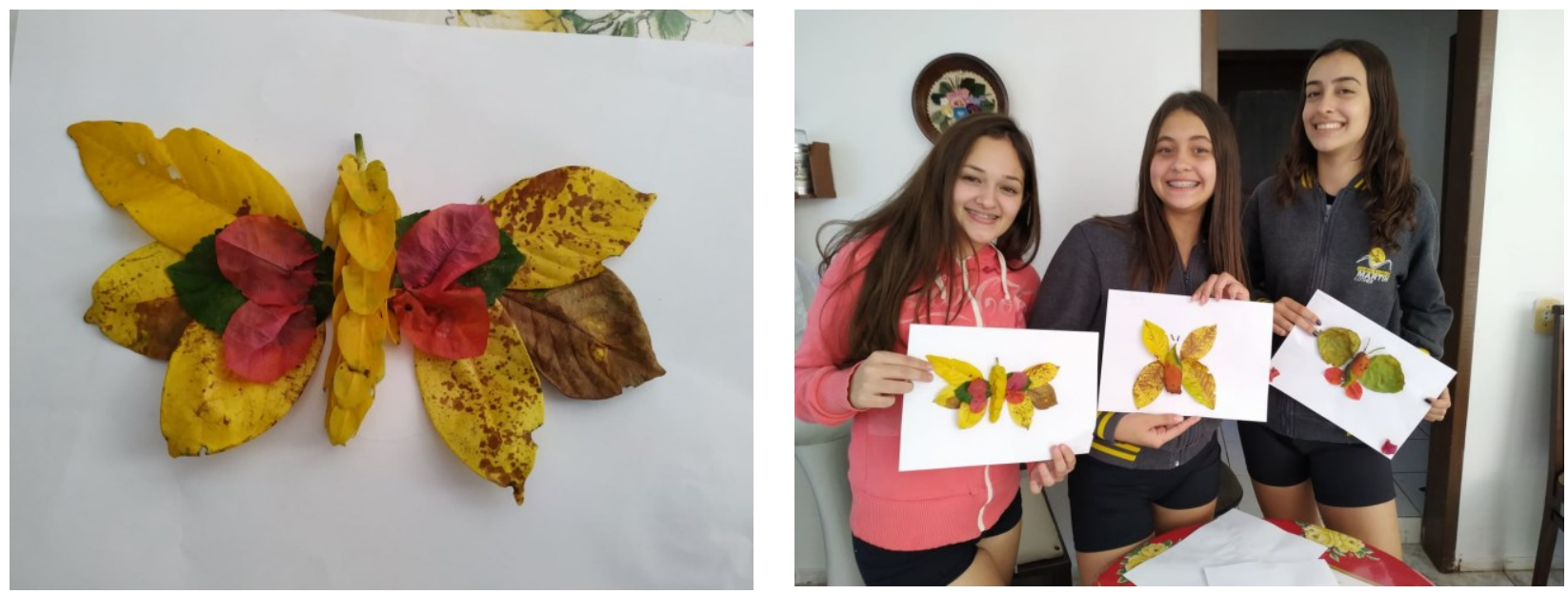

Fonte: Os autores, 2019.

O "Projeto Sítio Bier" é coordenado pela professora Idulce Ahlert, que organiza a visita de cada grupo de alunos com os professores de sua turma. Tudo é planejado anteriormente para que as atividades a serem desenvolvidas contemplem a dimensão da interdisciplinaridade e tragam posteriores momentos de estudo e reflexões em sala de aula concernentes a cada disciplina envolvida.

\section{Conclusão}

Conclui-se que o Ensino Religioso desenvolvido no Colégio Evangélico Martin Luther se constitui como parte importante para a vida dos alunos na Educação Básica. Ao articular o Ensino Religioso com a Educação Ambiental, a instituição amplia e enriquece as áreas em questão através do envolvimento dos alunos no "Projeto Sítio Bier", em suas relações com o meio ambiente saudável e preservado, no qual se trata a natureza na perspectiva do desenvolvimento rural sustentável. Isto, porém, não significa uma mera complementação. Seu enfoque é a abordagem religiosa e os conhecimentos científicos interdisciplinares, possibilitando questionamentos mais vastos e mais profundos para todas as disciplinas curriculares. Cumpre-se, assim, a tarefa de construir a crítica à destruição do meio ambiente e à perda de valores que afetam a vida humana e seu entorno ambiental, assim como desenvolver novos valores que contribuam para um desenvolvimento mais sustentável.

O desenvolvimento do projeto oportuniza aos alunos a interação e o conhecimento prático sobre a produção orgânica de alimentos de origem animal e vegetal e sobre a importância da reciclagem, do cuidado com os ecossistemas, da capacidade e importância da agricultura orgânica e do desenvolvimento sustentável, sobre a importância e o cuidado com a água, o ar e os problemas ambientais locais.

O projeto, ao articular o Ensino Religioso com as demais disciplinas, possibilita o aprendizado dos conteúdos curriculares de forma lúdica, com uma espiritualidade que desenvolve o cuidado com o meio ambiente, compreendido como a boa criação de Deus, e que deve ser como uma resposta ao seu amor redentor.

\section{Referências}

AHLERT, Alvori. Educação, ética e cidadania: referenciais para as escolas da Rede Sinodal de Educação. Beau Bassin, Mauritius: Novas Edições Acadêmicas, 2018.

Protestantismo em Revista | São Leopoldo | v. 45, n. 02 | p. 73-89| Jul./dez. 2019

Disponível em: <http://periodicos.est.edu.br/index.php/nepp> 
BRASIL. Manifesto pela Vida. Ministério do Meio Ambiente: por uma Ética para a Sustentabilidade. Governo Federal, s.d. Disponível em: http://www.mma.gov.br/estruturas/educamb/ arquivos/manifestovida.pdf. Acesso em 21 de Fev. 2019.

BOFF, Leonardo. Sustentabilidade: o que é: o que não é. 5. ed. Revista e ampliada. Petrópolis, RJ: Vozes, 2016.

CATÃO, Francisco. Diálogo. Revista da Religião. n. 11, São Paulo: Paulinas, Agosto, 1998.

GIL, Antônio Carlos. Métodos e técnicas de pesquisa social. 6. ed. São Paulo: Atlas, 2008.

JUNQUEIRA, Sérgio Rogério Azevedo, MENEGHETTI, Rosa Gitana Krob, WASCHOWICZ, Lilian Anna. Ensino Religioso e sua relação pedagógica. Petrópolis: Vozes, 2002.

JUNQUEIRA, Sérgio. O processo de escolarização do Ensino Religioso no Brasil. Petrópolis, RJ: Vozes, 2002.

KREUTZ, Lúcio. Escolas comunitárias de imigrantes no Brasil: instâncias de coordenação e estruturas de apoio. Revista Brasileira de Educação. ANPED, n. 15, 159-176, 2000.

KOPPE, Marise, AHLERT, Alvori, CARNIATTO, Irene. O desenvolvimento rural sustentável no currículo escolar. Revista GeoPantanal. UFMS/AGB, Corumbá/MS. N. 24, 251-268, jan./jun. 2018. Disponível em: https://periodicos.ufms.br/index.php/revgeo/article/view/6314 Acesso em: 03 Mar. 2019.

MALAFAIA, Guilherme; RODRIGUES, Aline S. de L. Uma reflexão sobre o ensino de ciências no nível fundamental da educação. Ciência e Ensino, v. 2, n. 2. 2008.

PAZZO, Juan Ignácio; CRESPO, Miguel Angel G. A aprendizagem e o ensino de ciências: do conhecimento cotidiano ao conhecimento científico. Tradução de Naila Freitas. 5. ed. Porto Alegre: Artmed, 2009.

PREDIGER, Caroline Luzia; AHLERT, Alvori. Ética e Educação Ambiental: Lugares Privilegiados na Apicultura. Ensaios e Cienc., v. 22, n. 2, p. 70-78, 2018. Disponível em: https://revista.pgsskroton.com.br/index.php/ensaioeciencia/article/view/5550/4589. Acesso em: 16 Ago. 2019.

ROCHA, Keili., AHLERT, Alvori., \& CARNIATTO, Irene. Área de Relevante Interesse Ecológico (ARIE) como espaço privilegiado para a Educação Ambiental. Revista Brasileira de Educação Ambiental (RevBEA), 12(4), 10-24, 2017. Disponível em: http://revbea.emnuvens.com.br/revbea/article/view/4964. Acesso em: 05 Ago. 2019.

SILVA, Calos Eduardo Mazzetto. Sustentabilidade. In: Caldart, Roseli Salete. (Org.) Dicionário da Educação do Campo. Rio de Janeiro, São Paulo: Escola Politécnica de Saúde Joaquim Venâncio, Expressão Popular, 2012, p. 730-734; p. 730.

STRECK, Danilo Romeu. Correntes pedagógicas: aproximações com a Teologia. Petrópolis, RJ: Vozes/CELADEC, 1994.

STRECK, Danilo R. \& WACHS, Manfredo C. Educação cristã. In: SCHNEIDER-HARPRECHT, Cristoph (Org.). Teologia Prática no contexto da América Latina. São Leopoldo: Sinodal: ASTE, 1998, p. 245267.

Protestantismo em Revista | São Leopoldo | v. 45, n. 02 | p. 73-89| Jul./dez. 2019

Disponível em: <http://periodicos.est.edu.br/index.php/nepp> 
STRECK, Danilo Romeu. Perspectiva luterana da educação (IECLB). In: STRECK, Danilo Romeu (Org.). Educação e Igrejas no Brasil: um ensaio ecumênico. São Leopoldo: Ciências da Religião/CELADEC/IEPG, 1995.

WIESSER, Lizete Carmen et alii. Parâmetros curriculares nacionais: Ensino religioso. 3. ed. São Paulo: Ave Maria, 1998.

WILSEK, Marilei Aparecida Gionedis, TOSIN, João Angelo Pucci. Ensinar e aprender Ciências no Ensino Fundamental com atividades investigativas através da resolução de problemas. Programa de Desenvolvimento da Educação, PDE, SEED-PR, 2008. Disponível em: www.diaadiaeducacao.pr.gov.br/portals/pde/arquivos/1686-8.pdf . Acesso em 25 Mai. 2019.

WENDLAND, Carlos Ernesto. O relógio perdido. In: NEUHAUS, Eloi Bruno (Org.). Semente de esperança. Palmitos: PPL, 2019. 